\title{
Economic Burden of Diabetes in Urban Indians
}

\author{
Pablo Chandra ${ }^{1,2,3}$, Bageshri Gogate ${ }^{4}$, Parikshit Gogate ${ }^{*}, 2$, Nilesh Thite ${ }^{1}$, Abhay Mutha ${ }^{5}$ and \\ Amit Walimbe ${ }^{6}$
}

\author{
${ }^{I}$ Bharti Vidyapeeth Medical College, School of Optometry, Pune, India \\ ${ }^{2}$ Community Eye Care Foundation, Dr. Gogate's Eye Clinic, Pune, India \\ ${ }^{3}$ West Bengal University Of Technology (Optometry Colleges), Kolkatta, Paschimbaga, India \\ ${ }^{4}$ Department of Pathology, Shrimati Kashibai Navale Medical College, Narhe, Pune, India \\ ${ }^{5}$ Diabetes Care and research Foundation, Pune, India \\ ${ }^{6}$ Walimbe Clinic, Pune, India
}

\begin{abstract}
Purpose: To find out the average economic burden of medical care on a patient with diabetes in Pune, India
Methods: A semi-open ended questionnaire followed by interview was conducted with patients attending diabetes and ophthalmic out-patient departments. They were asked regarding the duration of diabetes, methods undertaken for blood sugar control and the amount they spend on consultations, laboratory tests, medicines and procedures if any within past year. Expenditure was classified as direct cost (cost of medicines, doctor's fees, investigations, lasers and surgery) and indirect cost (travel, diet control, health classes and loss of wages). Data was collected regarding the socioeconomic status according to Kuppaswamy classification.

Results: 219 patients participated of whom 129 were males (58.9\%). Average annual direct cost of diabetes treatment was Rs 8,822 of which $52.1 \%$ was spend on medicines, $3.2 \%$ was spend on lasers, $12.6 \%$ was spend on surgical procedures, $11.6 \%$ spent on investigations and $10.4 \%$ was spend on clinician fees. Average annual indirect cost was Rs. 3949 of which $3.4 \%$ was spend on travelling purpose, $0.4 \%$ was spent on health classes, $4.9 \%$ was spent on diet control and $91.3 \%$ was loss of wages. Average expenditure done by lower middle class was $23.7 \%$ of their income. Average percentage of income for direct and indirect cost was 3.6\% and 1.4\% respectively. The cost of the treatment formed $1.3 \%$ of the annual income for those in Socio-economic class I, $1.7 \%$ in class II, $3.7 \%$ in class III and $23.7 \%$ in class IV.
\end{abstract}

Conclusion: The cost of managing diabetes was a significant proportion of the patients' income, especially for those on lower socio-economic scale (class IV).

Keywords: Cost of treatment, diabetes, economic burden, India.

\section{INTRODUCTION}

Diabetes mellitus (DM) is a group of metabolic disorders characterized by hyperglycemia. It is associated with abnormalities in carbohydrate, fat, and protein metabolism, and results in chronic complications, including retinopathy, nephropathy, and neuropathy (micro vascular) and ischemic heart disease, peripheral vascular disease, and cerebrovascular disease (macro vascular), resulting in organ and tissue damage in approximately one third to one half of people with diabetes $[1,2]$. The prevalence of DM has risen dramatically over the past two decades. It is estimated that the prevalence of diabetes in adults worldwide will rise to $5.5 \%$ in 2025 (as compared to $4 \%$ in year 1995), with India contributing the major part [3]. Researchers' estimate that by 2025 will be diabetic, nearly 300 million individuals shall be

*Address correspondence to this author at the Community Eye Care Foundation, Dr. Gogate's Eye Clinic, Pune, India;

Tel: +91-20-66027227; Fax: +91-20-26059723;

E-mail: parikshitgogate@hotmail.com diabetic [3]. There would be a $170 \%$ increase in developing countries with $>75 \%$ of diabetics residing in developing world [3]. India, China \& US would be the countries with the largest numeber of diabetics [2,3].

Asians have a strong ethnic and genetic predisposition for diabetes and have lower thresholds for the environmental risk factors $[3,4]$. As a result, they develop diabetes at a younger age and at a lower body mass index and waist circumference when compared with the Western population $[3,4]$. Today, India has about 50 million patients with diabetes and this number is projected to increase to 79.4 million by the year $2030.6-12 \%$ of urban and $2-3 \%$ of rural Indians have diabetes [4].

As the disease in chronic and progressive, it inflicts substantial cost of treatment on the patient and their facilities. The American Diabetic Association (ADA) estimated that the total economic cost of diabetes in 2012 was $\$ 245$ billion, compared to $\$ 132$ billion in $2002[5,6]$. On an individual level Grover $\mathrm{S}$ et al. had calculated that the mean annual cost of diabetes care was Rs. 14508 (\$290) to a 
patient of which $68 \%$ was direct cost and $28.8 \%$ indirect cost [7].

The aim of our study was to gauge the average economic burden of medical and eye care on a patient with diabetes in a large city in India. In lieu of this the direct and indirect expenditure on management of insulin dependent and non insulin dependent diabetes patients was studied. This was corelated with the duration of diabetes and social class.

\section{METHODS}

This study aimed to find out the cost of the individual which he/she had to incurs to comply with the treatment of diabetes. The cost was divided into two headings direct and indirect costs. Direct cost consisted of cost of medicines, doctor's fees, cost of investigations, cost of spectacles, and cost of lasers sittings for ocular complications and cost of surgery, if any. Indirect costs were expenditures incurred by patients for travelling to the doctor, in nutritional and dietary advice and wages or earnings lost because of treatment of diabetes. The respondents were assigned to different socioeconomic strata by the Kuppaswamy classification [8] and we tried to find the percentage of income spend on diabetes for different social classes. Kuppaswamy classification for socioeconomic grading was used in to grade the patient into different socioeconomic group to measure socio economic status of urban families. The original version 1976 version had been updated by Mishra and Singh in 2003 and Kumar et al. in 2007 [8]. The 2007 version was used for this study [8].

A semi open ended questionnaire was administered to patients attending two diabetic and one ophthalmology clinic. The questionnaire comprised of demographic questions, those related to socio economic status of the patient like monthly income, educational qualification, professional details which were used to classify the patient into different socio economic classes with the help of Kuppaswamy classification. The questionnaire also comprised questions regarding years of diabetes diagnosed, number of centers attending for ocular health and physical activities done. Clinical questionnaire also consist of number of laser sitting for diabetic treatment, number of surgical treatment done, number of glass changes done per year, number of times blood sugar check was done.

The questionnaire was framed by doing a focused group discussion with patients. The questionnaire consisted of 27 questions, and it was administered by a single investigator and was followed by a semi-structured Interview.

\section{RESULT}

Total 219 patients were screened and administered a questionnaire containing the questions regarding the cost. It was done in three clinics (one ophthalmic and two diabetic) from 1st of September 2011 to 31 st of January 2012. Out of total subjects, $129(58.1 \%)$ were males and 90 (41.1\%) were females. Their ages ranged from 21 to 80 years (mean $54.9 \mathrm{yrs}$, std dev 12.6 years) and they had been known diabetics for 2 to 34 years (mean 8 yrs, std dev 7.05 years). $86.4 \%$ were using oral anti diabetic agents while the rest were on insulin. $164(74.9 \%)$ participants had diabetes for 110 years, $46(21 \%)$ for $11-20$ years, $7(3.2 \%)$ for $21-30$ years while $2(0.9 \%)$ had it for $>30$ years.

The average monthly income of the sample was Rs. 20,000 out of which Rs.735 (3.6\%) was spent on direct cost and Rs. $329(1.4 \%)$ was spent on indirect cost. Average annual direct cost of diabetes treatment was Rs 8,822 of which $52.1 \%$ was spend on medicines, $3.2 \%$ was spend on lasers, $12.6 \%$ was spend on surgical procedures, $11.6 \%$ spent on investigations and $10.4 \%$ was spend on clinician fees. Average annual indirect cost was Rs. 3,949 of which $3.4 \%$ was spend on travelling purpose, $0.4 \%$ was spent on health classes, $4.9 \%$ was spent on diet control and supplements while $91.3 \%$ was loss of wages. There was a positive correlation with duration of diabetes $(P=0.013$ by using Fisher exact test). There was no significant difference in expenditure of patients on insulin and those on only oral anti-diabetic agents (by using 2 independent sample t-test $\mathrm{p}=$ $0.464)$.

Table 1 demonstrates the average monthly income of each social class. In social class I, $1.2 \%$ of monthly income was spent on direct cost for diabetes and $0.03 \%$ was used for indirect cost. In social class II, 3.6\% was spent on direct cost of diabetes and $2.4 \%$ was spent on indirect cost; while in social class III, 3.4\% was spent on direct cost of diabetes and $0.3 \%$ was spent on indirect cost; and in social class IV, $21.9 \%$ was spent on direct cost and $1.8 \%$ was spent on diabetes.

\section{DISCUSSION}

Diabetes is a chronic life style dieases that has numerous systemic and ocular manifestations. The cost of diabetes can be a major burden as the dieases does not have cure and its complications increase with increasing duration of the disease. This was seen in our study, a positive correlation of increasing cost with duration of diabetes $(P=0.013$ by using Fisher exact test). People with diagnosed diabetes, on

Table 1. Cost of treating diabetes as a proportion of monthly income for each social class of patients.

\begin{tabular}{|c|c|c|c|c|c|}
\hline \multirow{2}{*}{$\begin{array}{l}\text { Social } \\
\text { Class }\end{array}$} & \multirow{2}{*}{$\begin{array}{l}\text { Mean Monthly } \\
\text { Income (INR) }\end{array}$} & \multirow{2}{*}{$\begin{array}{l}\text { Mean Monthly } \\
\text { Direct Cost (INR) }\end{array}$} & \multirow{2}{*}{$\begin{array}{l}\text { Mean monthly indirect } \\
\text { cost (INR) }\end{array}$} & \multicolumn{2}{|c|}{$\begin{array}{c}\text { Percentage (\%) Money Spend with Respect to Mean Monthly } \\
\text { Income Type of Cost }\end{array}$} \\
\hline & & & & Direct Cost & Indirect Cost \\
\hline I & $103,125.00$ & $1,322.24$ & 25.94 & $1.3 \%$ & $0.03 \%$ \\
\hline II & $19,607.69$ & 701.02 & 483.91 & $3.6 \%$ & $2.5 \%$ \\
\hline III & $16,901.96$ & 576.76 & 53.45 & $3.4 \%$ & $0.3 \%$ \\
\hline IV & $4,785.71$ & $1,048.15$ & 84.50 & $21.9 \%$ & $1.8 \%$ \\
\hline
\end{tabular}

INR: Indian Rupees. 
average, have medical expenditures approximately 2.3 times higher than what expenditures would be in the absence of diabetes in developed countries like U.S. [6].

Our study demonstrate that patients spend an average of 2 to $5 \%$ of their family income on the disease. This is an consonanc with results published by Kumar A, et al., where direct cost consists of $1-3 \%$ of the gross family income [9]. Purchase of medicines was the chief economic burden accounting for almost half the direct expense of the disease followed by surgical(12.6\%) and Lasers treatment $(3.2 \%)$. The clamour for generic drugs that would greathy reduce the cost of medicines is serious and rightful issue and would greathy reduce the economic burden of this disease, especially in lower middle class and poor patients.

Of the average direct cost, only $10.4 \%$ was spent on doctor's consultation fees. Thus diabetic patients should be educated that if they have regular check ups the cost of managing their disease shall be less, not more, as their dieases would have fewer complications. Mohan et al. found that only $75 \%$ of residents in Chennai knew of diabetes [10]. Only $22 \%$ were aware that it was preventable, while only $12 \%$ knew of its risk factors. Even in known diabetics, only $40.6 \%$ were aware of its complications [10]. The amount spent on diet and health and gym facilities was negligible in this study. The medical fraternity, pharmaceutical industry and the governments need to increase awareness regarding the cause, preventable nature and potential complications if diabetes. Only proper health education would ensure that people take the disease seriously and ensure strict control by regular check-ups. On comparing the cost of treatment in patients who take insulin on a regular basis as compared to those who did not, suprisingly there was no statistically significant difference.

Patients in socioeconomic class III and IV spend a larger proportion of their income in managing diabetes in the latter upto one fourth of all their annual earning. One reason may be that the poor are less aware of the risk factors of diabetes and importance of regular monitoring and compliance and hence may be having more complications. Also the cost of managing the disease is significant as public hospitals (local and state government) do not offer medicines which have to be purchased. Over the past decade rapid economic growth, urbanisation, changes in lifestages, eating habits and household gadgets have improved calorie intake and reduced calorie output. This has to led rapid increase in diabetic population. Diabetes is no more a disease of the rich but is seen in middle, lower middle and poorer classes too. It is the latter ones who shoulder a disproportionate burden of the cost of managing diabetes.

Health insurance coverage in India is very less, and out of pocket payments predominate $[11,12]$. The government and few industries provides some cover to their employees. But in most cases this is limited to indoor hospital admissions and not out-patient consultations, investigations and pharmacy purchases that form the bulk of the economic burden of diabetes.

Diabetes unlike commen cold, typhoid, accidents, broken bones or cataracts is not a one time diease but one is the lifelong companion to the patient. Unless patients do not understand the cause and the risks of the dieases and its complication, good control is difficult and poor control is associated with spiralling cost. We hope our study shall promote more research into the economic consideration of diabetic treatment. It shall also spur physicians, ophthalmologist, optometrist and their health care providers to understand the ecconomic impact of this dieases on the patient and his family and find ways to minimise it.

Our study is limited by the fact that it was questionnaire based on walk-in patients in clinics. The expenses are as reported by the patients and thus subjective. We donot have data on those who did not visit doctors. Most of our patients were middle and lower middle class in an urban connubaration. We had asked about alternative medical therapy in our open ended question about what else the patient's do about diabetes. Many are known to try Ayurvedic preperations like those based on fenugreek but we did not elicit any significant responsee. Only $4.9 \%$ was spent on diet control and supplements. This may be an underestimation as respondents may be unwilling to disclose what is considered by some as not so scientific form of treatment.

This study demonstrates that patients spends a significant proportion of their income in managing diabetes. The portion gets more the lower in the economic class of the patient. Low income group patients spend upto one fifth of their income in managing the dieases.

\section{CONFLICT OF INTEREST}

The authors confirm that this article content has no conflict of interest.

\section{ACKNOWLEDGEMENTS}

Special thanks to Shrivallabh Sane for statistical analysis.

\section{Source of Funding}

Community Eye Care Foundation, Pune, India.

\section{APPENDICES}

Appendix A. Kuppuswami's method of classification (Urban) 2007 revision.

\begin{tabular}{|c|c|c|}
\hline & Item & Score \\
\hline \multirow{8}{*}{$\mathbf{A}$} & EDUCATION & \\
\hline & Professional degree, honors degree, post graduate degree & 7 \\
\hline & Graduation & 6 \\
\hline & Intermediate, post high school diploma & 5 \\
\hline & High school certificate & 4 \\
\hline & Middle school certificate & 3 \\
\hline & Primary school or literate & 2 \\
\hline & Illiterate & 1 \\
\hline \multirow{5}{*}{ B } & OCCUPATION & \\
\hline & Professional & 10 \\
\hline & Semi professional & 6 \\
\hline & Clerk, shop owner, farm owner & 5 \\
\hline & Skilled worker & 4 \\
\hline
\end{tabular}




\begin{tabular}{|c|c|c|}
\hline & Item & Score \\
\hline \hline \multirow{4}{*}{} & Semi skilled worker & 3 \\
\cline { 2 - 3 } & Unskilled worker & 2 \\
\hline \multirow{4}{*}{ C } & Unemployed & 1 \\
\cline { 2 - 3 } & PER CAPITA INCOME PER MONTH & \\
\cline { 2 - 3 } & 20,000 or more & 12 \\
\cline { 2 - 3 } & $10,000-19,999$ & 10 \\
\cline { 2 - 3 } & $7300-9999$ & 6 \\
\hline & $5000-7299$ & 2 \\
\hline
\end{tabular}

\section{Calculation}

Total score $=(\mathrm{A}+\mathrm{B}+\mathrm{C})$

26-29

16-25

$11-15$

05-10

$<05$

\section{APPENDIX - B}

\section{Data Collection Form}

Name:

Age:

Date:

Occupation:

Monthly Income:

\section{General Questionnaire:}

Since how many years you are having diabetes?

How many medical centers you have visited for ocular diabetes changes for last 5 years?

What physical activities you do for keeping diabetes under control, do you exercise? How many hours a week?

\section{Clinical Questionnaire:}

How many lasers sittings you have undergone for diabetic retinopathy treatment?

How many surgical procedures you have undergone for treating ocular diabetic changes?

How frequently you change your spectacles after consulting eye specialist?

How frequently you get your blood sugar checked?

\section{Expenditure Questionnaire:}

\section{Direct Cost:}

How much money you have spent on your spectacles 6 monthly?

How much you spend on your laser sittings?

How much money you spend on your surgical procedures?

How much you spend on medicines every monthly?

How much you spend for your clinician fees for diabetes/no. of visits/amount for each visit?

How much you spend on your investigative procedures?

\section{Indirect Cost:}

How much you spend on your traveling purpose for visiting to diabetes clinician?

How much you spend on your diet control package for your diabetes?

How much you spend on your health classes and physical training?

How much you spend on your miscellaneous expenses on the way to diabetes clinic and cost relating diabetes treatment.

\section{REFERENCES}

[1] Marshall SM, Flyvbjerg A. Prevention and early detection of vascular complications of diabetes. BMJ 2006; 333: 475-80.

[2] Ramchandran A, Snehalatha C. Current scenario of diabetes in India. J Diabetes 2009; 1: 18-28.

[3] King H, Aubert RE, Herman WH. Global burden of diabetes, 19952025: Prevalence, numerical estimates, and projections. Diabetes Care 1998; 21: 1414-31.

[4] Ramachandran A, Snehalatha C, Kapur A, et al. Diabetes Epidemiology study Group in India (DESI). High prevalence of diabetes and impaired glucose tolerance in India: National Urban Diabetes Survey. Diabetologia 2001; 44(9): 1094-101.

[5] American Diabetes Association. Economic Costs of Diabetes in US 2002. Diabetes Care 2003; 26: 917-932.

[6] American Diabetes Association. Economic Costs of Diabetes in US 2012. Diabetes Care 2013; 36: 1033-46.

[7] Grover S, Avasthi A, Bhansali A, Chakrabarti S, Kulhara P. Cost of ambulatory care of diabetes mellitus : a study from north India. Post Grad J 2005; 81: 391-5.

[8] Kumar N, Shekhar C, Kumar P, Kundu AS. Kuppusamy socioeconomic status scale updating for 2007. Indian J Pediatrics 2007 74: 1131-2

[9] Kumar A, Nagpal J, Bhartia A. Direct cost of ambulatory care of type 2 diabetes in the middle and high income group populace of Delhi. J Assoc Physician India 2008; 56: 667-74

[10] Mohan D, Raj D, Shanthirani CS, et al. Awareness and knowledge of diabetes in Chennai - The Chennai Urban rural Epidemiology study. J Assoc Physicians India 2005; 53: 283-7.

[11] Karan A, Selvaraj S, Mahal A. Moving to universal coverage? Trends in the burden of out-of-pocket payments for health care across social groups in India, 1999-2000 to 2011-12. PLoS One 2014; 9(8): e105162.

[12] Rao KD, Petrosyan V, Araujo EC, McIntyre D. Progress towards universal health coverage in BRICS: translating economic growth into better health. Bull World Health Organ 2014; 92(6): 429-35. 